\title{
Dynamic absolutism and qualitative change
}

\author{
Bahadır Eker ${ }^{1}$
}

\begin{abstract}
According to Fine's (Modality and tense: philosophical papers. Oxford University Press, Oxford, pp 261-320, 2005) famous take on the infamous McTaggartian paradox, realism about tensed facts is incompatible with the joint acceptence of three very general and seemingly plausible theses about reality. However, Correia and Rosenkranz (As time goes by: eternal facts in an ageing universe. Mentis, Paderborn, 2011) have recently objected that Fine's argument depends on a crucial assumption about the nature of tensed facts; once that assumption is given up, they claim, realists can endorse the theses in question without further ado. They also argue that their novel version of tense realism, called dynamic absolutism, is to be preferred over its rivals. I argue in this paper that dynamic absolutism does not constitute a genuine alternative for realists about tense.
\end{abstract}

Keywords Metaphysics of time $\cdot$ The A-theory of time $\cdot$ McTaggart's paradox $\cdot$ Kit Fine $\cdot$ Vicious infinite regress

Bahadir Eker

bahadir.eker@uni-tuebingen.de

1 Department of Philosophy, University of Tübingen, Bursagasse 1, 72070 Tübingen, Germany 


\section{Introduction}

In his seminal contribution to the philosophy of time, Fine (2005) has constructed a particularly incisive version of McTaggart's paradox. ${ }^{1}$ On Fine's construal of the argument, the problem with realism about tense (roughly, what is more colloquially known as the A-theory of time) is that it is incompatible with the joint acceptance of three very general and (at least prima facie) plausible theses about reality; so realism about tense must come at the cost of giving up at least one of them. However, Correia and Rosenkranz $(2011,2012)$ have recently objected that Fine tacitly assumes a particular view about the nature of tensed facts, and that once that assumption is dropped, the alleged incompatibility in question disappears. They also claim that the resulting version of realism about tense, called dynamic absolutism, ${ }^{2}$ is a better way out of Fine's argument than the alternatives.

I argue in this paper that dynamic absolutism does not constitute a genuine option for realists about tense. In the next section, I summarise Fine's argument and Correia and Rosenkranz's response to it. In Sect. 3, I develop an argument against dynamic absolutism in the form of a quadrilemma. Finally, in Sect. 4, I consider two possible replies on Correia and Rosenkranz's behalf and argue that neither of them is viable.

\section{Fine's McTaggart and dynamic absolutism}

As already mentioned, Fine's McTaggartian argument aims to show the incompatibility of realism about tense with three very general principles about the nature of reality. It is in fact a matter of some dispute how exactly these principles are to be understood, ${ }^{3}$ but here we can simply focus on Correia and Rosenkranz's (2012: 308-9) interpretation of them ${ }^{4}$ :

REALISM

Reality is constituted (at least, in part) by tensed facts.

NEUTRALITY

\footnotetext{
1 As is well known, this notorious argument, first presented in McTaggart (1908), has generated a huge literature, but see e.g. Cameron (2015: ch. 2), Skow (2015: ch. 6), Ingthorsson (2016), and Deasy (2018) for some recent discussion.

${ }^{2}$ In their (2011), Correia and Rosenkranz use the label absolutist anti-recurrentism for this view.

3 For critical discussion of Fine's argument, see Deng (2012), Tallant (2013), Cameron (2015: 86-102), Lipman (2015), Savitt (2016), Loss (2017, 2018), and Deasy (2018).

${ }^{4}$ Cf. also Correia and Rosenkranz (2011: ch. 4). I have serious reservations about their interpretation of some of these principles, but none of these matter in the present context. Note also that I have slightly altered Correia and Rosenkranz's wording.
} 
There are at least two distinct times, $t$ and $t^{\prime}$, such that some fact $f$ constitutes reality both at $t$ and at $t^{\prime} .5$

\section{ABSOLUTISM}

For any fact $f$, if there is a time $t$ at which $f$ constitutes reality, then there is no time $t^{\prime}$ such that $f$ does not constitute reality at $t^{\prime}$.

\section{COHERENCE}

For any facts $f$ and $f^{\prime}$, any fact-descriptions $d$ and $d^{\prime}$, and any time $t$, if, at $t$, $f$ and $f^{\prime}$ both constitute reality, $f$ satisfies $d, f^{\prime}$ satisfies $d^{\prime}$, then $d$ and $d^{\prime}$ are not incompatible. $^{6}$

To illustrate Fine's argument, as Correia and Rosenkranz understand it, let's look at a very simple example. Suppose that Fido is located at two times, $t_{1}$ and $t_{2}$, and it is brown all over at $t_{1}$ and orange all over at $t_{2}$. At $t_{1}$, then, a fact that satisfies the factdescription "The fact that, presently, Fido is brown all over" constitutes reality. Given ABSOLUTISM, this fact also constitutes reality at $t_{2}$. Yet at $t_{2}$, a distinct fact satisfying "The fact that, presently, Fido is orange all over" also constitutes reality, and again by ABSOLUTISM, as well as at $t_{1}$. But now it becomes clear that COHERENCE must thereby be violated: both at $t_{1}$ and at $t_{2}$, reality is constituted by facts that satisfy incompatible descriptions at both of those times.

Correia and Rosenkranz object that, for this argument to go through, one must assume the following principle:

FIXED CONTENT

For any fact $f$, any times $t$ and $t^{\prime}$, and any fact-description $d$, if $f$ constitutes reality at $t$ and $t^{\prime}$ and satisfies $d$ at $t$, then $f$ satisfies $d$ at $t^{\prime}$ as well.

Rejecting FIXED CONTENT, Correia and Rosenkranz argue, allows us to block the McTaggartian argument without having to give up any of the other principles Fine considers - and this precisely is the basic idea behind dynamic absolutism. On this view, reality is constitued by the very same tensed facts at all times-whichever time you consider, you always find the same stock of facts. However, although these facts remain numerically the same, they constantly undergo qualitative change and satisfy different fact-descriptions at different times. The simple story above involves, for instance, a fact that satisfies the fact-description "The fact that, presently, Fido is brown all over" at $t_{1}$. Call this fact $b$. Now the dynamic absolutist believes that $b$ constitutes reality also at $t_{2}$, as ABSOLUTISM requires, yet claims that it satisfies a different fact-description at that time, namely "The fact that, one day ago, Fido was brown all over". In our story, there is also the fact that satisfies "The fact that, presently, Fido is orange all over" at $t_{2}$, which we can call $o$. Just like $b$,

\footnotetext{
${ }^{5}$ Cf. Correia and Rosenkranz (2011: 57). I assume here that there is more than one single time and also that some fact constitutes reality at some time. Since, given these assumptions, ABsolutism entails NEUTRALiTY on Correia and Rosenkranz's interpretation of them, I shall simply ignore the latter principle in what follows.

6 A bit more precisely: two fact-descriptions "The fact that $p$ " and "The fact that $q$ " are incompatible iff $p$ and $q$ cannot both be true at the same time. Cf. Correia and Rosenkranz (2011: 50 and 88).
} 
$o$ constitutes reality at $t_{1}$ as well, but at that time, it satisfies the fact-description "The fact that, one day hence, Fido will be orange all over". So although $b$ and $o$ both constitute reality at all times, thanks to the constant qualitative change they undergo, there never is a time at which they satisfy incompatible fact-descriptions, and thus COHERENCE remains intact.

Correia and Rosenkranz argue further that the qualitative change in tensed facts is to be explained in terms of qualitative change in tensed properties. Take $b$ and $o$ once again. Each of these facts have two components, Fido and the tensed properties $\mathrm{B}$ and $\mathrm{O}$, so that we can symbolize them as [B(Fido)] and [O(Fido)], respectively. ${ }^{7}$ Now, on Correia and Rosenkranz's view, tensed properties like B and $\mathrm{O}$ themselves comprise two more basic elements: a proto-property and a tenseaspect. The proto-property of a tensed property is essential to it, but a tensed property undergoes qualitative change with respect to its tense-aspects. The protoproperty of the tensed property $\mathrm{B}$, for instance, is what we would intuitively call (all-over-)brownness. At $t_{1}$, B has the tense-aspect of presentness and satisfies the property-description "The property of being presently brown all over", but at $t_{2}$, it has the tense-aspect of one-day-pastness and satisfies the property-description "The property of having been brown all over one day ago". Since B is a component of the fact $[\mathrm{B}$ (Fido)], this constant qualitative change in the former is inherited by the latter.

Let's briefly take stock of the discussion so far. According to Correia and Rosenkranz, the kind of qualitative change that tensed facts undergo is the key to resisting Fine's argument. It is also supposed to be the only 'dynamic' element in this otherwise 'static' model-indeed, it is what "the passage of time ultimately consists in" 8 and is supposed to "explain in what sense reality changes as time goes by". 9 All the facts involving Fido constitute reality at all times, but those facts themselves are subject to change; even though Fido has all of its properties at all the times at which it exists, it does undergo change because those properties it has undergo change with respect to their tense-aspects. Or so the dynamic absolutist supposes.

\section{Facts about tense-aspects: a quadrilemma}

The main difficulty with dynamic absolutism, which takes the form of a quadrilemma, becomes apparent, once we put aside facts involving tensed properties of ordinary objects like Fido and focus instead on facts about the

\footnotetext{
7 As Correia and Rosenkranz (2011: 104) themselves acknowledge, given that tensed facts have their components essentially and that the components of a tensed fact must exist at $t$ if that fact constitutes reality at $t$ (Correia and Rosenkranz 2011: 104; 2012: 315), the dynamic absolutist is also committed to permanentism (Williamson 2013: 4; see also Deasy 2015 for discussion), the thesis that everything that exists at all, exists at all times-assuming, at least, that everything that exists is the component of some fact.

${ }^{8}$ Correia and Rosenkranz (2011: 122, 2012: 316).

9 Correia and Rosenkranz (2011: 99).
} 
tense-aspects of tensed properties. ${ }^{10}$ Let, for instance, " $[\tau(\mathrm{B})]$ " refer to the fact that the tensed property $\mathrm{B}$ has (or comprises) the tense-aspect of presentness - a fact that consitutes reality at $t_{1} \cdot{ }^{11}$ But do facts of this kind constitute reality not merely at this or that time, but rather at all times, just like all the other ordinary kind of facts? Now, and here is the first horn of the quadrilemma, a negative answer to this question seems unacceptable for the dynamic absolutist because it effectively means giving up ABSOLUTISM. But sticking to ABSOLUTISM only leads the dynamic absolutist to the second horn of the quadrilemma: for if facts about the tense-aspects of tensed properties are supposed to constitute reality at all times, reality seems to be constituted, at each and every time, by incoherent facts. [B(Fido)] and [O(Fido)] both constitute reality at $t_{1}$ as well as at $t_{2}$. Now if the tensed properties $\mathrm{B}$ and $\mathrm{O}$ both have the tense-aspect of presentness at both $t_{1}$ and $t_{2}$ (if, in other words, [ $\left.\tau(\mathrm{B})\right]$ and $[\tau(\mathrm{O})]$ also constitute reality at both $t_{1}$ and $\left.t_{2}\right)$, then, at both of these times, "The fact that, presently, Fido is brown all over" is satisfied by [B(Fido)] and "The fact that, presently, Fido is orange all over" by [O(Fido)]. Thus, if the dynamic absolutist holds on to ABSOLUTISM and allows facts about the tense-aspects of tensed properties constitute reality at all times, her account will violate COHERENCE. ${ }^{12}$

Of course, there is a familiar way of avoiding incoherent facts of the mentioned kind: facts about the tense-aspects of tensed properties can be 'internally' relativized to times. ${ }^{13}$ Accordingly, both at $t_{1}$ and at $t_{2}$, the facts about the tense-aspects of tensed properties would precisely be the following four: the fact that B has presentness at $t_{1}$, the fact that $\mathrm{B}$ has one-day-pastness at $t_{2}$, the fact that $\mathrm{O}$ has presentness at $t_{2}$, the fact that $\mathrm{O}$ has one-day-futurity at $t_{1}$. Clearly, these facts are not incoherent in any sense. But if the dynamic absolutist chooses this solution, then she cannot rightfully claim to endorse REALISM - for now it certainly seems that reality's being constituted by tensed facts is ultimately a matter of there being certain 'tenseless' facts about what tense-aspect what property has at what time. If

\footnotetext{
${ }^{10}$ See Loss (2018) for another argument against dynamic absolutism that is distinct from, but related to, the argument presented in this section. I am grateful to an anonymous referee for bringing this paper to my attention.

11 Correia and Rosenkranz (2012: 315, 2011: 120) emphasise that, ultimately, their account is supposed to involve no reference to, or quantification over, tense-aspects, even though they help themselves to them for the sake of convenience. For that same reason, I, too, shall continue to appeal to tense-aspects in the following, but note that the argument does not really hinge on this and can be reformulated without any reference to tense-aspects - instead of $[\tau(B)]$, for instance, we can refer to the fact that B is the property of being presently brown all over, which surely constitutes reality at $t_{1}$.

12 Applying ABSOLUTiSM to facts about the tense-aspects of tensed properties has further unsavoury consequences as well, given that $\mathrm{B}$ and $\mathrm{O}$ also have the tense-aspect of one-day-pastness at both $t_{1}$ and $t_{2}$. It would seem that $\mathrm{B}$, for instance, is, at both times, both the property of being presently brown all over and the property of having been brown all over one day ago, which is absurd. Moreover, if this were the case, then, at both times, [B(Fido)] would satisfy both "The fact that, presently, Fido is brown all over" and "The fact that, one day ago, Fido was brown all over", which contradicts an axiom Correia and Rosenkranz (2011: 47) explicitly endorse. Note also that, without further explanation, ordinary change in ordinary objects like Fido becomes quite mysterious: Fido is supposed to undergo change with respect to its colour, yet it always has the same tensed properties, which, in turn, always have the same tenseaspects.

${ }^{13}$ Cf. Fine (2005: 279-80, and also 271-4).
} 
the dynamic absolutist conceives of the facts about tense-aspects of tensed properties in this way, then her position is, as Fine (2005: 274) puts it, "realist in name only", ${ }^{14}$ which is the third horn of the quadrilemma.

But have not Correia and Rosenkranz already given us a recipe for construing tensed facts as constituting reality at all times without thereby violating COHERENCE? Indeed, why not apply the original solution to facts about the tense-aspects of tensed properties as well? Take, for instance, $[\tau(B)]$, the fact that B has presentness. We can suppose that this fact does constitute reality both at $t_{1}$ and $t_{2}$, as ABSOLUTISM requires, but undergoes qualitative change just like $[\mathrm{B}(\mathrm{Fido})]$. At $t_{1},[\tau(\mathrm{B})]$ is picked out by the description "The fact that, presently, B has presentness"; at $t_{2}$, that same fact is correctly described as the fact that, one day ago, B had presentness. Accordingly, although, at $t_{1}$, Fido is both $\mathrm{B}$ and $\mathrm{O}$, and $[\tau(\mathrm{B})]$ and $[\tau(\mathrm{O})]$ both constitute reality, at that time, $[\tau(\mathrm{B})]$ is the fact that, presently, $\mathrm{B}$ has presentness, whereas $[\tau(\mathrm{O})]$ is the fact that, one day hence, $\mathrm{O}$ will have presentness. Since facts about the tense-aspects of tensed properties undergo qualitative change along with the facts about the tensed properties of ordinary objects like Fido, the dynamic absolutist can still endorse both ABSOLUTISM and COHERENCE.

The problem with this last horn of the quadrilemma should be evident. In applying her account of qualitative change in facts to facts about the tense-aspects of tensed properties, the dynamic absolutist appeals, in effect, to second-order tenseaspects; hence, their metaphysics will include facts about the second-order tenseaspects of facts about the first-order tense-aspects of tensed properties, constituting reality at various different times. At $t_{1}$, for instance, reality is partly constituted by the fact that $[\tau(\mathrm{B})]$ has the second-order tense-aspect of presentness, whereas, at $t_{2}$, a (numerically or merely qualitatively) different fact, namely the fact that $[\tau(B)]$ has the second-order tense-aspect of one-day-pastness, partly constitutes reality. But now the above argument can be run once again, this time focusing on such facts about the second-order tense-aspects of facts about the first-order tense-aspects of tense properties, and the dynamic absolutist will have the very same options explored above. Thus, the idea of combining ABSOLUTISM and COHERENCE by rejecting FIXED CONTENT and invoking qualitative change in facts results in a vicious regress: at every given turn, one will be required to appeal to a higher order of tense-aspects in order to explain qualitative change in facts in question. ${ }^{15}$

\section{The regress and its viciousness}

The above argument seems very troubling for dynamic absolutism, but it is worth exploring how Correia and Rosenkranz might attempt to resist it. The first three horns of the quadrilemma are clearly unacceptable for dynamic absolutists, as they

\footnotetext{
14 In other words, the account would violate Fine's (2005: 273-274) 'No Collapse' requirement.

15 Cf. Fine (2005: 274-275). Incidentally, note that this discussion also brings out that McTaggart's paradox and the so-called problem of temporary intrinsics (Lewis 1986: 203-204) are the two sides of the same coin, as has been observed by many others (see e.g. Craig 1998; Rettler 2012; Ingthorsson 2016: 96; Cameron 2017: 821).
} 
each involve giving up one of the constitutive commitments of their view (indeed, the quadrilemma can be thought to boil down to a dilemma between effectively abandoning dynamic absolutism, which is supposed precisely to be a view that endorses all of the Finean principles, and generating a vicious regress). I suspect, therefore, that dynamic absolutists would rather target the fourth horn. More concretely, the dynamic absolutist might deny that there is any regress to worry about in the first place, or agree that a regress does indeed ensue, but dispute its viciousness.

One reason why the dynamic absolutist might want to deny that there is any regress, vicious or not, is that she might not be willing to admit any facts about the tense-aspects of tensed properties. Indeed, some of what Correia and Rosenkranz (2011: 122-125, 2012: 316-318) say when addressing the worry that all that dynamic absolutism has to offer is a B-theoretic metaphysics in disguise suggests that they might be attracted to a strategy of this kind. They respond to the said worry by arguing that, unlike in a B-theoretic model, there is room in their metaphysics for a property that can genuinely be gained and lost: the property of being present. This property is instantiated by times, which, according to Correia and Rosenkranz (2011: 110-111; 2012: 316), reduce to classes of contemporaneous tensed facts (that is, tensed facts that share the same tense-aspect or, more precisely, tensed facts that involve tensed properties with the same tense-aspect). Any such class $c$ has an index associated with it, which is "the number $n$ such that all members of $c$ have the tense-aspect of $n$-days-from-the-present-ness" (Correia and Rosenkranz 2012: 316). The property of being present is thus defined as "the property such that always, for all $x, x$ has it iff $x$ has index zero" (Correia and Rosenkranz 2012: 317). They (2012: 318 ) then raise a concern that is similar to the one that underlies the quadrilemma above:

It might, however, now be feared that once we admit the existence of a property that can be lost, we are bound to reject the absoluteness of constitution after all. For, supposing that a given object $x$ presently has a property $F$ and will fail to have that property one day hence, it would seem that the fact that $x$ has $F$ will presently constitute reality and fail to do so one day hence.

Correia and Rosenkranz's (2011: 124-125; 2012: 318) reaction to this concern is to deny that the fact-description "The fact that $\pi$ has the property of being present" (where $\pi$ names the present time) refers; they argue that the present truth of " $\pi$ has the property of being present" is to be explained instead by a universal fact, namely by the fact $u$ that for all facts $f$ that are members of $\pi, f$ has a tensed property as its component whose tense-aspect is presentness. They claim that " $[\mathrm{t}]$ here is indeed no problem in taking this universal fact to constitute reality absolutely" (2012: 318), as $u$ will also undergo qualitative change in accordance with the following principle: for all $n, n$ days from the present, $u$ is the fact that for all $f$ that are members of $\pi, f$ has a tensed property as its component whose tense-aspect is the tense-aspect of (n)-days-from-the-present-ness.

Whatever the merits of this response within its specific context, it certainly does not go nearly far enough to address the general issue raised in the previous 
section. Note first that Correia and Rosenkranz's refusal to assign a referent to the fact-description "The fact that $\pi$ has the property of being present" seems to be motivated, at least partly, by their reduction of times to classes of contemporaneous tensed facts; a similar reason does not seem available in the case of facts about the various qualitative states of tensed properties, however. Further, the above response appeals to a universal fact that is supposed to undergo qualitative change just as the ordinary facts about the tensed properties of objects do, and presumably, there will be certain facts about the various qualitative states of that universal fact (whatever exactly this might mean). But this is all that is needed to get the argument from the previous section going: suppose, for instance, that at some $t$, reality is partly constituted by the the fact $v$ that $u$ is the fact that for all facts $f$ that are members of $\pi, f$ has a tensed property as its component whose tense-aspect is presentness; the question is now whether $v$ constitutes reality not just at $t$, but also at all the other times, as is required by ABSOLUTISM, and if so, how this can be squared with COHERENCE (and, of course, REALISM). More generally: Correia and Rosenkranz argue that endorsing qualitative change in tensed facts is the key to reconciling the theses Fine takes to be jointly incompatible, and that qualitative change in tensed facts is grounded in the constant qualitative change that tensed properties undergo. Tensed properties are entities that Correia and Rosenkranz (2011: 103-105, 2012: 314-315) explicitly commit to, and their being in different qualitative states at different times plays a crucial explanatory role in their account. Thus, facts about the qualitative states of tensed properties are indispensable for the dynamic absolutist's metaphysics - dismissing their existence seems therefore not much of an option.

But perhaps there is no need, anyway, to try to avoid the infinite regress that dynamic absolutism seems to generate. Indeed, a theory's involving an infinite regress does not ipso facto constitute an objection to it, as in some cases, in certain theoretical contexts, an infinite regress is a completely harmless feature of a theory. If it turns out that the regress that the fourth horn of the quadrilemma above leads to is of this benign kind, then Correia and Rosenkranz have nothing to worry about, after all. ${ }^{16}$

Though it seems undisputed that at least some infinite regresses are vicious, it is far more controversial what the viciousness of vicious regresses consists in, what about a vicious regress makes it vicious, rather than benign. ${ }^{17}$ Still, many philosophers think that the viciousness of an infinite regress has something to do with the explanatory task it is meant to perform. Bliss (2013) has recently argued, for instance, that vicious infinite regresses typically involve a specific kind of "explanatory failure", and two of her comments on this are particularly relevant in the present context: that it "consists in the fact that the explanans is of the same form as the explanandum: the phenomenon for which we are seeking an explanation reappears as its own explanation", and that "[t]he problem is repeated at each level of the analysis, but it arises at the very first level" (Bliss 2013: 410). In a similar

\footnotetext{
${ }^{16}$ Many thanks to an anonymous referee for pressing me on this point.

17 Recent discussions of this question include Nolan (2001), Bliss (2013), and Cameron (2015: 58-63; 2018).
} 
vein, Ross Cameron (2015: 62) emphasises that, in a vicious infinite regress, the trouble is

not simply that a new question is generated with each answer, it is that the answer is always postponed.... At each stage, the explanation given relies for its success on the next puzzle being solved, but since each offered solution generates a new puzzle, the promise of explanation is always postponed and never fulfilled.

It may be that some infinite regresses are vicious without having any of these characteristics, ${ }^{18}$ but we can at least agree with Bliss and Cameron that those that do display these explanatory deficits are indeed vicious. To see that the regress dynamic absolutism generates is among the latter, let us examine the case a bit more closely. ${ }^{19}$ The central feature of Correia and Rosenkranz's response to Fine's argument is qualitative change in facts; it is this metaphysical doctrine that underlies their rejection of FIXED CONTENT and is supposed to reconcile the Finean principles. Thus, it is the explanandum we are interested in: we want to know how exactly qualitative change in tensed facts works. Correia and Rosenkranz tell us that facts change qualitatively, because they have components, tensed properties, that change qualitatively. But this response effectively appeals to certain facts about the various different qualitative states of tensed properties, and given Correia and Rosenkranz's metaphysical commitments, those facts themselves must undergo qualitative change. Hence, and this precisely is the crucial point, even at the initial stage, "the explanans is of the same form as the explanandum", as Bliss puts it: the dynamic absolutist tries to explain qualitative change in certain facts in terms of qualitative change in others, and since each new level of the regress introduces yet further facts that themselves must undergo qualitative change, the phenomenon we are interested in, qualitative change in facts, never actually gets explained. In order to understand how facts about Fido and its tensed properties change qualitatively, we need to understand how facts about the tense-aspects of Fido's tensed properties change qualitatively; and to understand the latter change, we need to understand how facts about second-order tense-aspects of the first-order tense-aspects of Fido's tensed properties change qualitatively; and so on ad infinitum. ${ }^{20}$ The problem certainly is not that the claim that facts undergo qualitative change gives rise to an infinity of ever higher-order facts, but rather that even that infinite amount of facts fails to answer the question we have asked at the very beginning. At any given stage of the regress, the explanatory buck is passed on to the next stage: we are simply

\footnotetext{
18 Bliss (2013: 410, fn. 35) herself mentions an exception that is also discussed by Nolan (2001: 525-526).

19 I am grateful to an anonymous referee for pressing me to elaborate on this.

20 Alternatively, we can also take the question of how ordinary objects like Fido change as our explanandum. According to the explanation Correia and Rosenkranz offer, Fido undergoes qualitative change despite having all of its properties at each and every time at which it exists, because its properties undergo qualitative change with respect to their tense-aspects. But given that Fido's properties must have all of their tense-aspects at all times (on pain of violating ABSOLUTISM), the dynamic absolutist will have to say that Fido's properties change because their first-order tense-aspects change with respect to their second-order tense-aspects. And so on, once again, ad infinitum.
} 
being told that the explanatory debt will be discharged by certain other facts, without any actual payment on the horizon.

\section{Conclusion}

In this paper, I have investigated whether Correia and Rosenkranz's dynamic absolutism can provide a satisfactory response to Fine's McTaggartian argument. The initial attraction of this alternative theory is its promise to reconcile the prima facie plausible principles Fine takes to be jointly incompatible. However, dynamic absolutists fail to deliver on this promise: their view either collapses into one of the versions of realism already recognized by Fine or else results in a vicious infinite regress. $^{21}$ Thus, in order to circumvent Fine's argument, tense realists still have to give up one of the three theses considered by Fine. ${ }^{22}$

Acknowledgements Open Access funding provided by Projekt DEAL.

Open Access This article is licensed under a Creative Commons Attribution 4.0 International License, which permits use, sharing, adaptation, distribution and reproduction in any medium or format, as long as you give appropriate credit to the original author(s) and the source, provide a link to the Creative Commons licence, and indicate if changes were made. The images or other third party material in this article are included in the article's Creative Commons licence, unless indicated otherwise in a credit line to the material. If material is not included in the article's Creative Commons licence and your intended use is not permitted by statutory regulation or exceeds the permitted use, you will need to obtain permission directly from the copyright holder. To view a copy of this licence, visit http:// creativecommons.org/licenses/by/4.0/.

\section{References}

Bliss, R. L. (2013). Viciousness and the structure of reality. Philosophical Studies, 166(2), 399-418. Cameron, R. (2015). The moving spotlight: An essay on time and ontology. Oxford: Oxford University Press.

Cameron, R. (2017). Reply to Miller, Sider and Skow. Analysis, 77(4), 810-824.

Cameron, R. (2018). Infinite regress arguments. In E. N. Zalta (Ed.), The Stanford encyclopedia of philosophy (Fall 2018 Edition). Retrieved October 16, 2019, from https://plato.stanford.edu/ archives/fall2018/entries/infinite-regress/.

\footnotetext{
21 Note that the argument presented above does not directly target the rejection of FiXED CONTENT; for all I have argued in this paper, there might be independent reasons to reject that principle. Hence, even if dynamic absolutism collapses into a non-absolutist version of realism about tense, for instance, it may constitute a distinctive variant of it that rejects FIXED CONTENT (for whatever reason). The point is simply that rejecting FIXED CONTENT does nothing to help one circumvent Fine's argument. I am grateful to an anonymous referee for urging me to clarify this.

22 Earlier drafts of this paper were presented at the Graduate Colloquium in Theoretical Philosophy at University of Tübingen and the workshop "The Now Now" at University of Siegen; many thanks to the audiences on these occasions for helpful discussion and feedback, especially to Thomas Sattig, Tobias Wilsch, Florian Fischer, and Cord Friebe. I am also indebted to two anonymous referees for their critical comments and useful suggestions.
} 
Correia, F., \& Rosenkranz, S. (2011). As time goes by: Eternal facts in an ageing universe. Paderborn: Mentis.

Correia, F., \& Rosenkranz, S. (2012). Eternal facts in an ageing universe. Australasian Journal of Philosophy, 90(2), 307-320.

Craig, W. L. (1998). McTaggart's paradox and the problem of temporary intrinsics. Analysis, 58(2), $122-127$.

Deasy, D. (2015). The moving spotlight theory. Philosophical Studies, 172(8), 2073-2089.

Deasy, D. (2018). Philosophical arguments against the A-theory. Pacific Philosophical Quarterly, 99(2), 270-292.

Deng, N. (2012). Fine's McTaggart, temporal passage, and the A versus B-debate. Ratio, 26(1), 19-34.

Fine, K. (2005). Tense and reality. Modality and tense: Philosophical papers (pp. 261-320). Oxford: Oxford University Press.

Ingthorsson, R. D. (2016). McTaggart's paradox. London: Routledge.

Lewis, D. (1986). On the plurality of worlds. Oxford: Blackwell.

Lipman, M. A. (2015). On Fine's fragmentalism. Philosophical Studies, 172(12), 3119-3133.

Loss, R. (2017). Fine's McTaggart: Reloaded. Manuscrito, 40(1), 209-239.

Loss, R. (2018). Fine's trilemma and the reality of tensed facts. Thought, 7(3), 209-217.

McTaggart, J. M. E. (1908). The unreality of time. Mind, 17(68), 457-474.

Nolan, D. (2001). What's wrong with infinite regresses? Metaphilosophy, 32(5), 523-528.

Rettler, B. (2012). McTaggart and indexing the copula. Philosophical Studies, 158(3), 431-434.

Savitt, S. (2016). Kit Fine on tense and reality. Manuscrito, 39(4), 75-99.

Skow, B. (2015). Objective becoming. Oxford: Oxford University Press.

Tallant, J. (2013). A heterodox presentism: Kit Fine's theory. In R. Ciuni, K. Miller, \& G. Torrengo (Eds.), New papers on the present: Focus on presentism (pp. 281-305). Munich: Philosophia Verlag.

Williamson, T. (2013). Modal logic as metaphysics. Oxford: Oxford University Press.

Publisher's Note Springer Nature remains neutral with regard to jurisdictional claims in published maps and institutional affiliations. 